\title{
PRÁTICAS EDUCATIVAS EM ESPAÇOS E SUJEITOS SEGREGADOS E SEGREGADORES
}

\author{
Angela Rosani Fontana dos Santos ${ }^{2}$ \\ Elisa Machado Menta Baggio ${ }^{3}$ \\ Lilian Carla da Silva Santos ${ }^{4}$ \\ Neide Alves dos Santos Scandolara ${ }^{5}$
}

\section{RESUMO}

O objetivo deste artigo é o de analisar as práticas educativas e diversidades culturais em espaços e sujeitos segregados e segregadores, enfocando exclusão, inclusão e segregação em todas as suas formas. Esta investigação se deu através da coleta de informações com entrevistas estruturadas, onde o entrevistado teve a liberdade de opinião sobre as questões propostas, bem como através de estudos e análises de documentos que ampliem as informações propiciando subsídios para a fundamentação da pesquisa, onde seus resultados foram analisados. As entrevistas foram aplicadas com 76 detentos, alunos do Centro Estadual de Educação Básica para Jovens e Adultos - CEEBJA Novos Horizontes - Ensino Fundamental e Médio. Levando em conta as contribuições dessa pesquisa para repensar e fundamentar a visão sobre as práticas educativas no meio prisional, pode-se dizer que o melhor ganho está na compreensão de novas concepções sobre o assunto, possibilitando a reflexão e apreensão das teorias educacionais que se referem às atuações dos educadores e suas práticas em ambientes prisionais.

Palavras-chave: Práticas educativas. Inclusão. Exclusão. Reinserção. Segregados. Segregadores.

\footnotetext{
${ }_{1}^{1}$ Aluna do Curso de Pós- graduação Stricto Sensu da Faculdad de Ciencias de la Educación, Universidad de la Empresa-UDE.

${ }^{3}$ Aluna do Curso de Pós- graduação Stricto Sensu da Faculdad de Ciencias de la Educación, Universidad de la Empresa-UDE.

${ }^{4}$ Aluna do Curso de Pós- graduação Stricto Sensu da Faculdad de Ciencias de la Educación, Universidad de la Empresa-UDE.

${ }^{5}$ Aluna do Curso de Pós- graduação Stricto Sensu da Faculdad de Ciencias de la Educación, Universidad de la Empresa-UDE.
} 


\section{INTRODUÇÃO}

O processo de inclusão iniciou nos anos 90, durante a Convenção Mundial de Educação Para Todos, onde foram aprovados pelas Nações Unidas diversos artigos, os quais acastelavam o direito e a democratização da educação para todos, sem distinção. A ponderação nesse artigo abarca a inclusão e a reintegração, enfatizando a necessidade de dar oportunidade a todas as pessoas, em especial aos detentos(as). Importante ressaltar que embora diferente, o indivíduo possui aptidões, suscetíveis de serem trabalhadas e desenvolvidas.

Embora existam diferenças socioculturais no Brasil, as situações problemáticas que surgem no sistema prisional têm características semelhantes.

$O$ alto índice de reincidência e a superlotação refletem uma crise no sistema que repercute fora dos seus muros. Contudo, podemos afirmar que essa crise não nasceu na prisão, apenas se agravou. Pensar a educação como uma válvula de escape para os problemas do sistema carcerário é mascarar a realidade de desigualdade e exclusão do nosso país. Por outro lado, é importante refletir sobre o papel da educação dentro deste sistema (SILVA, 2011, p. 28).

As instituições escolares, que se desenvolvem dentro e fora da prisão, que possuem como intuito a educação de jovens e adultos devem perceber a heterogeneidade de seus sujeitos e colocar em prática estratégias que atendam essa realidade. Ou seja, medidas que levem os educandos a permanecerem na instituição a fim de prosseguir su curso escolar e de aprendizagem. Pode-se dizer que a insuficiência de políticas sociais com o intuito de minimizar as desigualdades sociais no País pode levar à superlotação dos presídios (SILVA, 2011).

Pensar a educação escolar em lugares de falta de liberdade leva a questões: Como lidar com o contrassenso da cultura prisional, marcada pela coerção, ordem e disciplina, muitas vezes utilizada para amoldar o indivíduo ao cárcere? Como implantar o preceito essencial da educação, que é transformador e libertador? A educação prisional deve ter por objetivo a inclusão ou reinserção social?

Este artigo tem como objetivo analisar as práticas educativas e diversidades culturais em espaços e sujeitos segregados e segregadores, enfocando exclusão, inclusão, reinserção e segregação em todas as suas formas.

A inclusão a ser tratada neste trabalho é um tema que vem levando os professores a repensarem as suas práticas, quando se nota em prisões os multíplices olhares dos professores frente à 
inclusão na heterogeneidade. O intuito desse trabalho é levar os que crêem na possibilidade de inclusão e reintegração, a visualizarem o dessemelhante como um ser com capacidades e aptidões.

A educação enquanto ferramenta de desenvolvimento humano entende o indivíduo como histórico, apto a produzir e reproduzir, de ampliar-se em suas diversas dimensões, de intervir e mudar a realidade (SILVA, 2011). Corroborando com essa ideia, enfatiza-se Paulo Freire que melhor defendeu a formação do educador e o educando na ação que leve à suplantação e à humanização.

A metodologia utilizada foi a pesquisa bibliográfica, embasada na perspectiva teórica de vários autores que versam sobre exclusão, integração e inclusão, segregados e segregadores, dentro do sistema prisional. Foi utilizada a pesquisa documental, onde foram avaliados os documentos legais que versam sobre a temática, a fim de embasar o debate sobre as práticas educacionais nas prisões.

Fez-se uso de pesquisa de campo, com a finalidade de refletir e contribuir para a análise das práticas pedagógicas e suas implicações na conjuntura da aprendizagem com os indivíduos privados de liberdade. Bem como, a observação direta e a aplicação de questionários e entrevistas com os educandos detentos.

Neste artigo foram enfocados os referenciais teóricos referentes à questão da educação, inclusão, reinserção e diversidade. Desta maneira, é expressivo ressaltar que foram destacadas as diversas ideias de pessoas que se empenharam a estudar a temática da inclusão, reinserção e exclusão, segregados e segregadores dentro do sistema prisional.

\section{FUNDAMENTAÇÃO TEÓRICA}

\subsection{EDUCAÇÃO COMO DIREITO DE TODOS}

A educação consiste em um direito de todo o cidadão, legitimado pela Constituição e confirmado por documentos internacionais firmados pelo governo do Brasil.

A Declaração Mundial de Educação Para Todos de 1990, estabelece que o verdadeiro papel da escola que é a de acatar a todos. O documento institui o direito à educação e o acesso ao 
conhecimento, e as escolas na visão da diversidade devem abrigar todos, de forma autônoma em todas as situações.

No entanto, a abonação de acesso à educação não beneficia a todos, nomeadamente para uma das partes colocadas de lado na sociedade: as pessoas que cumprem pena em prisões. Sendo que o Art.205 - CF de 1988 diz que: "A educação, direito de todos e dever do Estado (...), será promovida e incentivada com a colaboração da sociedade, visando ao pleno desenvolvimento da pessoa, seu preparo para o exercício da cidadania e sua qualificação para o trabalho" (BRASIL, 1988).

Nessa acepção é de essencial ressaltar Costa e Gonçalves Júnior (2008, p. 8), quando enfatizam:

- A individualidade - cada um deve ter direito a satisfazer suas necessidades e seus interesses;

- A identidade - o que significa aceitar as peculiaridades e as diferenças, possibilitando o desenvolvimento da personalidade de cada um, aferir-Ihe autonomia e autoconfiança positiva;

- Os ideais democráticos - que representa a busca de equidade, isto é, da equiparação de oportunidades;

- A retirada de barreiras para que o acesso de todos ao processo de aprendizagem; Segundo ainda os autores supracitados (2008, p. 8) "pensar no outro, no diferente, na diversidade, é pensar na possibilidade de reduzir e eliminar as barreiras do preconceito, da discriminação e da desigualdade". Nesta conjuntura, Dussel (2001 apud OLIVEIRA, 2006, p. 70) assevera que:

Aceitar o argumento do outro supõe-se o aceitar o outro como igual, e esta aceitação do outro como igual é uma posição ética, é o reconhecimento ético ao outro como igual, quer dizer, aceitar o argumento não é somente uma questão de verdade, é, também uma aceitação da pessoa do outro.

Portanto, na visão de obter o direito à educação para todos os indivíduos, devem fazer parte os que estão privados de liberdade, pois, esses necessitam a chance de se integrarem novamente à vida em sociedade.

Segundo Gadotti (2009, p. 6):

Parece evidente, para todos, que a educação é necessária para a obtenção da liberdade e o exercício da cidadania, tornando as pessoas mais independentes e mais felizes. O direito à educação é reconhecido no 
artigo 26 da Declaração Universal dos Direitos Humanos como direito de todos ao "desenvolvimento pleno da personalidade humana" e para fortalecer o "respeito aos direitos e liberdades fundamentais". A conquista deste direito depende do acesso generalizado à educação básica, mas o direito à educação não se esgota com o acesso, a permanência e a conclusão desse nível de ensino: ele pressupõe as condições para continuar o estudo em outros níveis.

Como direito, a educação deve ser constante, em situações de equidade para todos, intercultural, que afiance a integralidade e a intersetorialidade. Direito este que deve ser asseverado pelo Estado, fixando a dedicação das classes sociais mais vulnerabilizadas.

Para colocara em prática esse direito, o Estado necessita prevalecer-se do potencial da sociedade civil na concepção de políticas públicas relacionadas à educação e dar impulso ao desenvolvimento de preceitos altruístas de educação, com base na colaboração, e na reinserção social.

Segundo Mészáros (2005, p. 65),

O papel da educação é soberano, tanto para a elaboração de estratégias apropriadas e adequadas para mudar as condições objetivas de reprodução, como para a auto mudança consciente dos indivíduos chamados a concretizar a criação de uma ordem social metabólica radicalmente diferente.

Relevante enfatizar que a aplicação de capital na educação de presos é feita com vistas à recuperação dos mesmos, isto é, com a finalidade de reinserção social, que, vem sendo interpretada como inclusão social.

Saraiva; Lopes (2011, p. 16) defendem essa ideia da seguinte forma:

[...] os apenados brasileiros, embora vivam em situação de segregação da sociedade, não são excluídos do cuidado estatal. Eles estão inseridos dentro do sistema prisional, que se constitui parte importante da sociedade contemporânea. Na condição de reclusos, sofrem investimentos governamentais que visam à vigilância e ao controle maximizado de suas condutas para que possam, dentro do sistema em que estão incluídos, serem reinseridos na vida em sociedade.

Nessa visão, reinserção social difere de inclusão social. Isto porque a reinserção implica na propensão dos sujeitos coexistirem em sociedade, livres e independentes. Portanto, a educação do recluso, buscando a sua reinserção social, deve ser estabelecida por meio de políticas.

A prisão continuaria sendo o lugar de incentivar a obediência e quebrar a iniciativa e a capacidade de gestão da própria vida, docilizando corpos. Ao mesmo tempo em que os presos adquirem esses 
aprendizados informais e essenciais, a prisão vai, devido à sua estrutura, ensinar a desaprender, ensinar a ser passivo (MAEYER, 2006 apud SARAIVA; LOPES, 2011, p. 16).

Para o autor supracitado, é necessário o desenvolvimento de novas formas de educação que revigorem o sentido da educação, que é reconhecer-se e ser bom como ser humano.

\subsection{TRAJETÓRIA LEGAL DA EDUCAÇÃO NAS INSTITUIÇÕES PRISIONAIS}

A educação prisional, obteve, ao longo dos tempos, diversos documentos legais que validaram sua implementação e desenvolvimento. Silva (2011, p. 17), cita os seguintes documentos:

- A Lei de Execução Penal, em seus Arts. 17 e 18, dispõe que a assistência educacional compreenderá a instrução escolar e a formação profissional, com o ensino de primeiro grau sendo obrigatório; no art. 19, determina que o ensino profissional seja ministrado em nível de iniciação ou de aperfeiçoamento técnico. Aos que prezam a leitura é necessário que se faça um processo de conscientização, demonstrando os benefícios que o direito pode trazer dentro e fora do cárcere (BRASIL, 1984).

- Lei de Diretrizes e Bases - LDB-1996 -define a Educação de Jovens e Adultos como destinada a pessoas que não tiveram acesso ou continuidade de estudos no ensino fundamental e médio na idade própria. Referendando o que está posto na Constituição Federal (BRASIL, 1996).

- Plano Nacional de Educação - PNE- Implantar em todas as unidades prisionais e nos estabelecimentos que atendam menores infratores, programa de EJA nas etapas fundamental e médio, assim como a formação profissional (BRASIL, 2014).

- A Declaração Universal dos Direitos Humanos reconhece o direito humano à educação em seu artigo 26 e estabelece que o objetivo dele é o pleno desenvolvimento da pessoa humana e o fortalecimento do respeito aos direitos humanos (BRASIL, 1948).

- Resolução no 03 do CNPCP de 11 de março de 2009, que dispõe sobre as Diretrizes Nacionais para Oferta de Educação nos Estabelecimentos Penais (BRASIL, 2009).

- Resolução CNE/CEB no 02 de 19 de maio de 2010, que estabelece Diretrizes Nacionais para a Oferta de Educação para Jovens e Adultos em Situação de Privação de Liberdade nos Estabelecimentos Penais (BRASIL, 2010). 
- As Diretrizes Curriculares Nacionais para oferta de Educação para Jovens e Adultos em situação de liberdade nos estabelecimentos penais, de 2010. Destaca em seu inciso VIII do art. 3, a oferta de educação para jovens e adultos será organizada de modo a atender as peculiaridades de tempo, espaço e rotatividade da população carcerária levando em consideração a flexibilidade prevista no art. 23 da LDB-9394-96 (BRASIL, 2010).

- Lei de Diretrizes e Bases da Educação Nacional (LDB) no 9.394, de 20 de dezembro de 1996; Lei $n^{\circ}$ 12.513, de 26 de outubro de 2011, que institui o Programa Nacional de Acesso ao Ensino Técnico e Emprego (Pronatec). Considerando o ambiente prisional um local de aprendizagens, onde o ser humano um sujeito histórico e social (BRASIL, 2011).

- Lei no 12.513, de 26 de outubro de 2011, que institui o Programa Nacional de Acesso ao Ensino Técnico e Emprego (Pronatec) (BRASIL, 2011).

- Decreto № 7.626 de 24 novembro de 2011 que institui o Plano Estratégico de Educação no Sistema Prisional - PEESP (BRASIL, 2011).

- De acordo com a de Lei de Execução Penal a assistência educacional é obrigatória para o ensino do primeiro grau e compreenderá a formação profissional, já o trabalho tem finalidade educativa e produtiva, é descrito como um dever social e condição de dignidade humana e deve ser remunerado. Além disso, por meio do trabalho o preso tem direito à remição da pena, como diz Lei no 12.433, de junho de 2011, altera a LEP que trata da remição da pena pelo estud. (BRASIL, 2011 apud SILVA, 2011).

- No Paraná, a Lei Estadual n. 17.329 instituiu a remição da pena por estudo por meio da leitura desde 2012 (PARANÁ, 2012).

Nesse contexto, deve-se refletir sobre o papel desempenhado pela educação nas instituições prisionais.

\subsection{EDUCAÇÃO NAS PRISÕES: EXCLUSÃO, INCLUSÃO OU REINSERÇÃO?}

Segundo Santos (2006, p. 316) "temos o direito a ser iguais sempre que a diferença nos inferioriza; temos o direito a ser diferentes sempre que a igualdade nos descaracteriza". 
É importante enfatizar que não se educa para algo ou para alguém. Educação constitui um direito e, por isso, deve ser afiançado de maneira igualitária, equânime e justa. Segundo Gomes (2012, p. 35):

A finalidade da educação e das suas políticas não é formar indivíduos para o mercado, para o vestibular ou atingir os índices internacionais de alfabetização e matematização. O foco central são os sujeitos sociais, entendidos como cidadãos e sujeitos de direitos que são também diversos em raça, etnia, credo, gênero, orientação sexual e idade, entre outros.

Ao estabelecer como primazia de acolhimento do direito à educação as categorias sociais mais desamparadas, deve-se adicionar aí os analfabetos bem como os apenados, isto considerando o ambiente prisional um local de aprendizagens, onde o ser humano é um sujeito histórico e social. Corroborando Freire (1980, p. 34) diz que "para ser válida a educação deve considerar as condições em que o homem vive num exato lugar, momento e contexto". Desse modo, as ações educativas nas instituições prisionais devem ser ponderadas a partir de suas particularidades.

Assim, a exclusão da vivência do preso aumenta o risco de exclusão social e a prisão se torna um depósito dos resultados de suas mazelas sociais.

Fator agravante dessa situação é a ausência de políticas públicas eficazes nas áreas sociais que estão intrinsecamente associadas à marginalização e criminalidade da população pobre. Diante dessa realidade, a perspectiva do preso para uma qualidade de vida e reintegração social fica reduzida, senão, nula. Porém, cabe refletir sobre a ausência do Estado no atendimento às necessidades básicas da sociedade em geral e não poderia ser diferente para a população carcerária (SILVA, 2011, p. 15).

Todavia, a educação nas prisões ainda não é atendida como direito de todos, mas sim, como uma regalia para o aprisionado.

Para Santos (2007 apud CARVALHO, 2012, p. 99) "o universo prisional guarda algumas especificidades que são relevantes e que marcam decisivamente as práticas dos sujeitos que convivem em seu interior, quer do corpo dirigente, funcional e ou/, ainda, da massa encarcerada". Sobre o assunto, Goffman diz que:

Esse universo é assinalado por elementos, como "a linguagem, os valores, as normas, as crenças, a ciência, a educação, a repressão, violência, a ordem, a disciplina que muitas vezes manifestam de forma velada em suas teias de relações. As unidades prisionais priorizam a manutenção da ordem, isolamento, segurança e disciplina e muitas vezes tornam-se quase impenetráveis a mudanças. Dentre algumas de 
suas características principais está o não reconhecimento dos encarcerados como sujeitos (GOFFMAN, 1997 apud CARVALHO, 2012, p. 99).

A prisão tem suas normas, comportamentos e suas regras, condutas e seus princípios, peculiares, constituindo-se um campo de discussões e conflito entre os seus componentes. As atividades educacionais. As atividades educacionais estão entre as contempladas no sistema prisional, tendo como um dos seus desafios a concepção da cidadania em termos de autonomia, livre-arbítrio, alteridade, em prol de uma sociedade justa e humana. Para isso é necessário a materialização do currículo carcerário.

Infelizmente, a disciplina do cárcere imputado aos detentos constitui um entrave à educação, pois se entende que não é possível falar em "pedagogia do cárcere", onde o domínio pela disciplina e a reeducação do apenado estão interligadas. Segundo Foucault:

Trata-se do acréscimo do termo educar ao binômio vigiar e punir. Num contínuo processo de normalização, o carcerário se instala em toda a sociedade. Do mesmo modo, a parafernália disciplinar, pela via do educacional, se estende pela prisão, objetivando e assujeitando os detentos, de maneira a produzir indivíduos que se constituem por processos de aprendizagens, adaptações, introjeções e assimilações concretizados no espaço prisional. A partir desse horizonte pode-se falar numa "educação penal", ou "reeducação legal", em que os gestores da pena assumem o papel de mestres da normalidade (FOUCAULT, 1991 apud SILVA, 2011, p. 17).

A "pedagogia do cárcere" engloba uma dimensão de educação voltada para a disciplina que se usa para modificar e reeducar os detentos. Além disso, o direito de todos à educação se reduz aos internos de baixa periculosidade, o que significa que atinge apenas uma parcela.

Para Onofre (2007):

Os presos fazem parte da população dos empobrecidos, produzidos por modelos econômicos excludentes e privados dos seus direitos fundamentais de vida. Ideologicamente, como os "pobres", aqueles são jogados em um conflito entre as necessidades básicas vitais e os centros de poder e decisão que as negam. São, com certeza, produtos da segregação e do desajuste social, da miséria e das drogas, do egoísmo e da perda de valores humanitários. Por sua condição de presos, seu lugar na pirâmide social é reduzido à categoria de "marginais", "bandidos", duplamente excluídos, massacrados, odiados (ONOFRE, 2007, p.12).

São percursos de vivências equivalentes e que se tramam nos mesmos obstáculos, onde os indivíduos privados de liberdade representam as mazelas sociais do país. Entretanto, não se pode dizer que os presos são apenas vítimas sociais, desconexo do dolo cometido, pois são indivíduos que possuem direitos iguais aos demais que gozam de liberdade. 
Para Julião (2007), é proposital o valor que se dá ao trabalho em detrimento do estudo, porque:

Negando o ócio, portanto, o trabalho no sistema penitenciário caracteriza-se como a adição do castigo à produção de bens e serviços. Já que trabalho pressupõe produção, nada mais favorável para os agentes operadores da justiça do que utilizar o trabalho como instrumento de reinserção social, visto que estão diretamente dando a oportunidade a indivíduos improdutivos (delinquentes) de se tornarem produtivos (JULIÃO, 2007 apud SILVA, 2011, p. 43).

Frente aos empecilhos para se concretizar a educação como direito e privilégio social, os detentos que frequentam a EJA nas instituições prisionais ficam reféns de normas e iniciativas compensatórias, fazendo com que as reivindicações precisas para a área fiquem esquecidas.

Deve-se ressaltar que a prisão, nos moldes da disciplina empregada, não estaria mais sendo benévola como tática de correção e inserção para a existência em sociedade, mas teria a conotação segregação aqueles que se representam um risco para a segurança.

Analisando a produção teórica que hoje predomina no campo educacional, podemos perceber que as orientações sobre o modo como se devam conduzir as práticas pedagógicas não visariam produzir corpos dóceis, mas constituir subjetividades empresárias de si, que tomam para si a responsabilidade de sua própria vida, sem esperar um comando externo. Dentro desse contexto, podemos depreender que uma Educação que persiga esse objetivo deve incentivar autonomia e independência, o que é corroborado pelos enunciados encontrados nas publicações analisadas: "Para educar, para se educar, é preciso ter uma visão otimista do futuro" (MAEYER, 2006 apud SARAIVA; LOPES, 2011, p. 46).

Assim sendo, o encarceramento com bases em medidas disciplinares apenas não leva à recuperação. A educação prisional deve estar pautada numa educação contemporânea abarcando as "teorias freirianas, que defendem como base conceitual a questão emancipatória, uma educação libertária, visando uma transformação significativa da sociedade de forma positiva" (SILVA; KAYSER, 2015, p. 6).

Corroborando essa ideia, Urpia (2009) diz que:

Como regra geral, valem os princípios já enunciados pela Unesco de que "todos aprendemos por toda a vida" e "todos podemos nos (re)educar por toda a vida". Tais princípios são sustentadores na lógica educativa implicada pelo neoliberalismo. Ao partirmos da crença na capacidade do indivíduo em se educar e ao atribuirmos a ele essa responsabilidade, entendemos que quando isso não acontece ou quando a educação de alguém deixa a desejar -considerando uma determinada norma local, é porque ou o indivíduo "não tem interesse" em se educar, ou porque não possui condições de buscar sua educação. Esses dois casos exigem medidas distintas. (URPIA, 2009 apud SARAIVA; LOPES, 2011, p. 19). 
Estudiosos como Schultz (1973) analisaram a educação como sendo "um investimento no capital humano". Ou seja, seria:

[...] o que permite a cada um inserir-se no sistema produtivo e auferir renda a partir de seu trabalho. Inúmeras iniciativas do Estado são mobilizadas por distintas instituições que se dedicam a educar os presos para a liberdade. Isso implica em fazê-los "esquecer" outras aprendizagens para assumir aquela que se apresenta como condição necessária para uma outra forma de vida, mesmo que esta vida esteja e permaneça sob reclusão (SCHULTZ (1973) apud SARAIVA e LOPES, 2011, p. 25).

Sendo assim, os detentos não são preparados para a saída do presídio. O que aprendem todos os dias são condutas, valores e redes que não condizem com essa preparação (MAEYER, 2006 apud SARAIVA; LOPES, 2011, p. 4).

Relevante enfatizar que o investimento na educação de apenados é feito com vistas à recuperação dos mesmos, isto é, com a finalidade de reinserção social, que, vem sendo entendida como inclusão social. Sabe-se que na prática a reeducação do egresso é quase inexistente, porque o principal intuito do sistema penitenciário não é a reeducação do preso, mas sim a privação de sua liberdade.

Interessante ressaltar que muitos presos se valem da chance para se educar, o que não ocorreu antes de serem detidos. O ser humano é plausível de recuperação, mesmo que isso impetre um trabalho espinhoso e pertinaz ao educador. Talvez, seja o maior repto dessa Educação, irromper com as visões de educação já materializadas, como disciplinadora, repreensora, excludente, superando a relação oposta opressor/oprimido, implantando uma nova relação constituída de liberdade, igualdade e emancipação, preferindo assim uma educação libertadora (FREIRE, 2001).

\section{MÉTODO E ANÁLISE DOS RESULTADOS}

Esta investigação se deu através da coleta de informações com entrevistas estruturadas onde o entrevistado teve a liberdade de opinião sobre as questões propostas, bem como através de estudos e análises de documentos que ampliem as informações propiciando subsídios para a fundamentação da pesquisa, tendo seus resultados analisados e transcritos pelos pesquisadores. As entrevistas foram aplicadas com 76 detentos, alunos do Centro Estadual de Educação Básica para Jovens e Adultos - CEEBJA Novos Horizontes - Ensino Fundamental e Médio. O questionário era formado por perguntas abertas e fechadas, onde algumas admitiam mais de uma resposta. 
A primeira questão referia-se aos motivos que os levaram a frequentar a escola. Pelas respostas dos detentos, constatou-se que dezessete (17) deles acreditam que o estudo facilita o acesso ao trabalho, após saírem da prisão; trinta e um (31) por remição; para concluir o curso, trinta e seis (36); e, para adquirir novos conhecimentos, dezesseis (16) detentos.

Em referência a maior dificuldade enfrentada dentro da Penitenciária, em relação à discriminação de raça, cor, gênero, credo, classe social, artigo, as respostas dos detentos indicaram que trinta e quatro (34) detentos nunca sofreram discriminação; discriminados pelo artigo, foram dezesseis (16); os que não responderam foram cinqüenta (50).

A terceira questão referia-se à prática pedagógica desenvolvida pelos professores. Se esta contribuía para minimizar está discriminação. As respostas dos presos demonstraram que cinqüenta e oito (58) dos detentos entrevistados aprovam a prática desenvolvida, pois esta contribui de forma ética e igualitária, enquanto que dezoito (18) não responderam.

Sobre a questão de seguirem padrões de hierarquia criados pelos detentos dentro da Penitenciária, as respostas incidiram em 50 dos entrevistados seguem hierarquia; onze (11) não seguem nenhuma hierarquia e, quinze (15) não responderam.

A pergunta relativa à forma como essa hierarquia e normas afetam o cotidiano, vinte e um (21) dos entrevistados responderam que ela afeta o dia a dia; trinta e sete (37) responderam que não afeta em nada; e, dezoito (18) não responderam.

Sobre a última questão, cinqüenta e nove (59) detentos consideram que as regras de convívio criadas entre os detentos e as "penalidades" aplicadas entre os mesmos, são uma forma de demonstrar poder ou são, necessárias para o bom andamento na Unidade penal e não interferem nas suas permanências. Já dezessete (17) não responderam.

Dentro dessa conjuntura, ao avaliar a influência mútua do apenado na Penitenciária foi detectado que o preso, ao coexistir dentro da prisão, muitas vezes, interatua de maneia negativa a uma proposição de coletivização. Foi percebido que o sistema prisional contribui para destruí-lo como cidadão. E esse resultado é conciliável com a análise de Foucault (1991 apud SILVA, 2011), quando este menciona que o sistema prisional não ressocializa o indivíduo, apenas castiga.

A pesquisa possibilitou constatar que as pertinências de força e poder instaladas na prisão com certeza constituem os medos e angústias dos detentos. Os impactos abarcando presos e 
funcionários fazem da segregação uma peculiaridade importante e sempre presente em uma instituição penal, avigorando situações de violação de direitos.

Segundo Bauman (1999), pode-se entender que a prisão é uma instituição destinada a segregar e afastar e até a eliminar. Sendo assim, de tal maneira falar em direitos particulares como discorrer sobre direitos econômicos, sociais e culturais, pode-se encontrar, na prisão, uma grande incidência de infrações de direitos.

Através de observação, verificou-se que dentro da instituição prisional, existe uma hierarquia, onde os mais velhos e os mais ameaçadores exercem influência sobre os demais, e a luta pelo domínio entre eles é constante. A maneira com que os presos modificam a coexistência entre eles é análoga com o que Foucault (1991 apud SILVA 2011) expõe sobre os processos de objetivação que acontecem nos circuitos de poderes. Entre os presos, a categorização e divisão em relação a quem tem maior e, ou, menor poder, os que são mais acatados e temidos, e os que devem obedecer.

Pode-se notar também que a convivência entre presos e agentes penitenciários na prisão é bastante tumultuada, onde se observa a resistência de domínio nessas relações. Por sua vez, os agentes penitenciários exercem o papel de vigilante, de carrasco, de disciplinador de presos; e, de outro lado estão os presos resistindo a essas demandas.

É essencial que se pense sobre o tipo de cidadãos que a educação oferecida nas instituições prisionais deseja, buscando repensar as políticas que afiancem a todos o acesso aos direitos constitucionais (saúde, educação, trabalho, lazer, entre outros). Nessa probabilidade, é importante que o sistema carcerário brasileiro possa ser estimado e repensado numa forma que propenda a integrar o indivíduo na sociedade, desconexo do delito perpetrado.

Ações eficazes deveriam ser estabelecidas, que garantissem recuperar e oferecer possibilidades de qualidade de vida ao delinquente, dentro e fora da instituição, o que com certeza evitaria tão elevadas taxas de reincidência, as superlotações, hoje comuns nos presídios já existentes.

Para ocorrer uma melhora desse quadro, concebe-se a necessidade de estabelecer políticas públicas mais dinâmicas para combater a ação criminosa do indivíduo na sociedade. Além disso, sugere-se que a educação oferecida nos sistemas prisionais, incida em práticas pedagógicas humanizadoras e conscientizadoras, a fim de que ela seja uma condição de recuperação de vidas. A noção de educação enquanto direito humano preconiza o direito do apenado a uma escola 
competente, solidária, produtiva e libertadora. Uma educação escolar que favoreça a autonomia intelectual dos alunos, proporcionando-Ihes situações para análise e apreensão da realidade prisional, humana e social em que vivem. Que ela seja instrumento não apenas para resistir à lógica de funcionamento das prisões, mas, ao mesmo tempo para ajudar a dar novas acepções para a política penitenciária.

Uma administração prisional que tenha compromisso com o acesso a uma educação como "prática de liberdade", (FREIRE, 2001), pode buscar os embasamentos da "segurança" no respeito aos Direitos Humanos e não como ferramenta para sujeição que habitualmente organizam a convivência nas prisões.

\section{CONSIDERAÇÕES FINAIS}

Na realidade, o cárcere é nefasto ao condenado, impetrando-Ihe implicações devastadoras, pois afasta a dignidade do ser humano e sua condição de cidadão.

A educação nas instituições prisionais precisa gerar a cultura da paz nas distintas configurações de coexistência social, mostrando que a reclusão e a falta liberdade muitas vezes, ajudam no aumento da reincidência nos presídios. Alcançar educação de qualidade dentro dos presídios necessita repensar a prática educacional e estabelecer objetivos que visem uma educação humanizadora.

Pensar a educação como um ato benevolente para o indivíduo privado de liberdade é refrear o seu direito, é preciso reconhecer os detentos como público da Educação de Jovens e Adultos em suas peculiaridades. Também não é possível crer que apenas a educação poderá dar conta das questões que estão intrinsecamente ligadas à inadequação política, social e econômica. Assim, a não concretização do direito à educação, em qualquer campo social é, apenas, um reflexo desse desajuste. Os caminhos possíveis desta pesquisa permitiram evidenciar a necessidade de aprofundar a reflexão sobre o sério problema da exclusão social no sistema prisional, existente no país e é uma temeridade afiançar que a educação conseguirá dar solução a isso.

Fatores externos ao sistema prisional, tais como: falta de renda, moradia, cor da pele, tipo de crime tem impactado na exclusão e influenciam o processo de escolarização dos encarcerados. 
Pelos estudos realizados, constatou-se que refletir sobre uma Educação Prisional que tenha como parte essencial o homem presidiário e não a visão do preso. Que contribua para a remissão desse sujeito, através de um currículo arrojado, renovador e maleável e não esquecendo as perspectivas do saber e da cultura.

Levando em conta as contribuições dessa pesquisa para repensar e fundamentar a visão sobre as práticas educativas no meio prisional, pode-se dizer que o melhor ganho está na compreensão de novas concepções sobre o assunto, possibilitando a análise e entendimento das teorias educacionais relacionadas às práticas educativas em ambientes prisionais.

\section{REFERÊNCIAS}

BAUMAN, Z. Globalização: As consequências humanas. Rio de Janeiro: Jorge Zahar, 1999.

BRASIL. Constituição Federal. 1988. Disponível em: www.planalto.gov.com.br. Acesso em: 10 mar 2017.

CARVALHO, R. É. Educação inclusiva: com os pingos nos "is". 4ª ed. Porto Alegre, Mediação, 2006.

CARVALHO, O. F. A educação escolar prisional no brasil: identidade, Diretrizes legais e currículo. Interfaces da Educ., Paranaíba, v.3, n.9, p.94-105, 2012. Disponível em: https://periodicosonline.uems.br/index.php/interfaces/article/view File/ 557/521. Acesso em: 03 abr 2017.

COSTA, V. B. da; GONÇALVES JUNIOR, L. Inclusão, educação e diversidade: múltiplos olhares- SPQMH/NEFEF/UFSCar Área Temática: Educação: Diversidade e Inclusão Agência Financiadora: IFP-FCC 2008. Disponível em: https://pt.scribd. com/document/290688979/COSTA-E-GONCALVES-JUNIOR-Sd-Inclusao-Educacao $-\mathrm{e}-$ Diversidade-Multiplos-Olhares. Acesso em: 04 abr 2017.

FREIRE, P. Educação como prática da liberdade. 25. ed. São Paulo: Paz e Terra, 2001.

FREIRE, P. Conscientização: teoria e prática da libertação. São Paulo: Cortez e Moraes, 1980.

GADOTTI, M. Educação de adultos como direito humano. Editora e Livraria Insti. Paulo Freire. 2009. 
GOMES, N. L. Diversidades e desigualdades na educação. Educação \& Sociedade. Educ. Soc. vol.33 no.120 Campinas July/Sept. 2012. Disponível em: www.cedes.unicamp.br. Acesso em: 20 mar 2017.

MÉSZÁROS, I. A educação para além do capital. Tradução de Isa Tavares. São Paulo: Boitempo, 2005.

OLIVEIRA, I. A. de. A problemática da ética da diferença e da exclusão social: um olhar dusseliano. In: MARTINS, Lúcia de Araújo Ramos. et. al. [orgs.]. Inclusão: compartilhando saberes. Petrópolis: Vozes, 2006, p.67-77.

ONOFRE, E. M. C. Escola da prisão: espaço de construção da identidade do homem aprisionado? UFSCar / SP GT: Educação Popular / n. 06.

SARAIVA, K.; LOPES, M. C. Educação, inclusão e reclusão. Currículo sem Fronteiras, v.11, n.1, pp.14-33, Jan/Jun 2011. Disponível em www.curriculosem fronteiras.org. Acesso em: 10 mar 2017.

SANTOS, B.S. A construção intercultural da igualdade e da diferença. In: SANTOS, B.S. A gramática do tempo. São Paulo: Cortez, 2006. p. 279-316.

SILVA, M. A.; KAYSER, A. M. O papel da educação contemporânea, uma reflexão a partir da pedagogia da autonomia de Paulo Freire ISSN 1982-4866. Revista Dynamis. FURB, Blumenau, v. 21 , n. 2 , p. $3-15,2015$

SILVA, L. Ribeiro. A escola no sistema prisional. Curso de Pedagogia - Gestão e Coordenação do Trabalho Escola Universidade do Estado da Bahia. Departamento de Educação - Campus 1 [Monografia]Salvador. $2011 . \quad$ Disponível em: http://www.uneb.br/salvador/dedc/files/2011/05/Monografia-Lucineide-Ribeiro.pdf. Acesso em: 20 mar 2017. 